\title{
The Effectiveness of Post-Exposure Prophylaxis in Infants Born to Hepatitis B Virus Positive Mothers in the Kurdistan Region, Iraq
}

\author{
Amira S. Khalil, ${ }^{1}$ Warveen L. Abdulkareem, ${ }^{2}$ and Nawfal R. Hussein ${ }^{2,}{ }^{*}$ \\ ${ }^{1}$ Gynecology Hospital, Duhok, Kurdistan Region, Iraq \\ ${ }^{2}$ Department of Internal Medicine, Azadi Teaching Hospital, College of Medicine, University of Duhok, Duhok, Kurdistan Region, Iraq \\ "Corresponding author: Nawfal R. Hussein, Department of Internal Medicine, Azadi Teaching Hospital, College of Medicine, University of Duhok, Duhok, Kurdistan Region, \\ Iraq, E-mail: Nawfal.hussein@yahoo.com
}

Received 2016 September 19; Revised 2016 October 05; Accepted 2016 October 06

Keywords: Vertical Transmission, HBV, HBIG, Vaccine, Duhok, Iraq

\section{Dear Editor,}

Infection with hepatitis B virus is a public health problem particularly in developing countries $(1,2)$. Chronic HBV may predispose to liver failure, cirrhosis and hepatocellular carcinoma (1). In addition, chronic HBV infection puts a heavy burden on the health system of third world countries such as Iraq. Public health planers have laid out an ambitious plan to reduce the transmission of the virus in the city of Duhok, Kurdistan Iraq. The plan is composed of two main parts: pre-exposure and post-exposure prophylaxis. Pre-exposure prophylaxis includes vaccinating all newborn babies as well as anyone who is at risk, such as health care workers. The main target for post-exposure prophylaxis is to intercept perinatal mother-to-child transmission (or perinatal vertical transmission). In high-risk areas, all pregnant women should be screened for HBV as well as checking if positive for HBeAg. HBeAg is a marker of viral replication and its positivity is associated with high viral loads. The chance of mother-to-child transmission is ranging from $10 \%$ in mothers who are negative for $\mathrm{HBeAg}$ to up to $90 \%$ in mothers who are positive with HBeAg. Once the infection is acquired, the chronic infection would be established in $90 \%$ of the newborns. Such an infection in one's early life is associated with a high morbidity and mortality (3). Hence, screening pregnant women for HBV is mandatory here in Duhok. Administering a HBV vaccine and giving hepatitis B immune globulin (HBIG) immediately after birth for newborns of infected mothers are efficient means for the prevention of perinatal transmission and therefore help reduce the HBV infection in the whole population (1). This strategy of post-exposure prophylaxis can eliminate up to $95 \%$ of vertical transmission (4). In this project, we aimed to study the effectiveness of our verti- cal transmission prevention measures in the city of Duhok. Throughout the period of January 2015 to January 2016, 95 HBV at term pregnant women visited the Duhok Maternity Hospital. 93/95 (97.9 \%) were HBe-Antigen (HBeAg) negative with an undetectable HBV viral load. 28/95 (29.4\%) of those women needed to have a caesarian section for their delivery. According to the local protocol, irrespective to the mean of delivery and HBeAg positivity, all infants of HBV infected mothers should receive HBIG and should receive the first, second and third dose of the vaccine at birth, 2 months and 6 months after birth, respectively. After the completion of the prophylaxis program, all infants were tested for HBsAg and anti-HBs antibodies (HBsAb). All of the subjects were negative for HBsAg and 94/95 (98.9\%) of infants' HBsAb titers were $\geq 10 \mathrm{IU} / \mathrm{L}$. These results are in agreement with a study conducted in Iran where only $2.6 \%$ of the infants acquired the infection in spite of the prophylaxis measures. In the same study, more than $94 \%$ of the infants achieved a titer of higher than $10 \mathrm{IU} / \mathrm{L}$ (5). Furthermore, our results are in agreement with data published by the centers for disease control (CDC) proposing that HBIG and three doses of vaccine can prevent the HBV infection in newborns of HBV infected mothers with an effectiveness of $85 \%$ to $95 \%$ (6). The achievement of protective HBsAb levels in this study was higher than that previously achieved in adults where only $85 \%$ of the subjects achieved the protective levels (7). In conclusion, the post-exposure prophylaxis measures in Duhok are effective in preventing mother-tochild transmission. More studies are needed to explore the successfulness of other preventive measures.

\section{References}

1. Edmunds WJ, Medley GF, Nokes DJ, O'Callaghan CJ, Whittle HC,

Copyright ( ) 2016, Infectious Diseases and Tropical Medicine Research Center. This is an open-access article distributed under the terms of the Creative Commons Attribution-NonCommercial 4.0 International License (http://creativecommons.org/licenses/by-nc/4.0/) which permits copy and redistribute the material just in noncommercial usages, provided the original work is properly cited. 
Hall AJ. Epidemiological patterns of hepatitis B virus (HBV) in highly endemic areas. Epidemiol Infect. 1996;117(2):313-25. doi: 10.1017/S0950268800001497. [PubMed: 8870629].

2. Hussein NR, Haj SM, Almizori LA, Taha A. The Prevalence of HBV and HCV among Blood Donors Attending Blood Bank in Duhok city, Kurdistan region, Iraq. IntlJ Infect. 2016;inpress(inpress). doi: 10.17795/iji39008.

3. Chang MH, You SL, Chen CJ, Liu CJ, Lee CM, Lin SM, et al. Decreased incidence of hepatocellular carcinoma in hepatitis B vaccinees: a 20-year follow-up study. J Natl Cancer Inst. 2009;101(19):1348-55. doi: 10.1093/jnci/djp288. [PubMed: 19759364].

4. Gentile I, Borgia G. Vertical transmission of hepatitis B virus: challenges and solutions. Int J Womens Health. 2014;6:605-11. doi: 10.2147/IJWH.S51138. [PubMed: 24966696].

5. Ahmadinejad Z, Abdi Liae Z, Salehizadeh S, Mansori S, Alijani N. Efficacy of Post-Exposure Prophylaxis in Infants Born to HBsAg Positive Mothers in Iran; Is It Authentic? Iran J Pediatr. 2016;26(3):5979. doi: 10.5812/ijp.5979.

6. [No authors listed]. Protection against viral hepatitis. Recommendations of the Immunization Practices Advisory Committee (ACIP). MMWR Recomm Rep. 1990;39(RR-2):1-26. [PubMed: 2153904].

7. Hussein NR. Prevalence of HBV, HCV and HIV and Anti-HBs antibodies positivity in healthcare workers in departments of surgery in Duhok City, Kurdistan Region, Iraq. Int JPure Applied Sci Technol. 2015;26(2):70. 